\title{
Pertautan Citra Tampak Atas dengan Metode Stereoskopik untuk Menghilangkan Distorsi Perspektif
}

\author{
Endang Pertiwi*1 ${ }^{1}$, Bambang Nurcahyo Prastowo ${ }^{2}$, Lukman Awaludin ${ }^{3}$ \\ ${ }^{1}$ Program Studi Elektronika dan Instrumentasi, FMIPA, UGM, Yogyakarta, Indonesia \\ ${ }^{2,3}$ Departemen Ilmu Komputer dan Elektronika, FMIPA UGM, Yogyakarta, Indonesia \\ e-mail: *11endang.pertiwi@mail.ugm.ac.id, ${ }^{2}$ prastowo@mail.ugm.ac.id, \\ ${ }^{3}$ lukman.awaludin@ugm.ac.id
}

\begin{abstract}
Abstrak
Pertautan citra dengan jarak objek yang berbeda-beda terhadap kamera dan relatif dekat akan menghasilkan citra panorama dengan distorsi perspektif (menghasilkan objek ganda ataupun objek hilang) karena kamera memantau dalam bentuk dua dimensi dengan jarak horizontal antar kamera yang besar. Untuk mengatasi persoalan tersebut, digunakan metode stereoskopik dengan memberikan persepsi kedalaman tiga dimensi dari dua citra dengan latar yang sama sehingga dapat diketahui informasi kedalaman suatu objek dengan cara yang intuitif.

Penelitian ini menghadirkan sistem dengan segmentasi ROI untuk masing-masing objek yang bersifat statis yang kemudian akan dilakukan pertautan pada tiap-tiap objek dan kemudian digabungkan kembali menjadi suatu citra panorama dari gabungan dua pertautan objek yang nantinya akan ditampilkan dalam bentuk citra. Deskriptor SIFT digunakan untuk mendeteksi dan mengekstraksi fitur pada citra yang diolah. Sistem yang dihadirkan berhasil menampilkan hasil penggabungan dari pertautan masing-masing objek yang bersifat statis.
\end{abstract}

Kata kunci-pertautan citra, stereoskopik, distorsi perspektif

\begin{abstract}
Stitching citra with different object's depth and disposed close to the camera willing caused panoramic citra with distortion perspective (caused double or disappear object) because the camera see in two dimension with large horizontal disparity by each camera. For solve that problem, stereoscopic method purpose to give depth perception of three dimension from two images with same background so information of depth by the object be able to get with intuitive way.

This research presented system with ROI segmentation for any static objects, stitching for each objects and combine them become a panoramic image then shown in citra panoramic. SIFT descriptor used for detect and extract feature from the images. The result of this system successful presented combination for stitching by the static objects.
\end{abstract}

Keywords—image stitching, citra stitching, stereoscopic, distortion perspective 


\section{PENDAHULUAN}

CCTV (Closed-Circuit Television) merupakan sistem video yang digunakan untuk keperluan pengawasan dan penjagaan, sehingga dapat memudahkan manusia dalam hal pemantauan [1]. Peletakan kamera/sudut pandang kamera juga perlu diperhatikan agar sistem dapat memantau area yang diamati dengan baik. Pada umumnya kamera diletakkan pada posisi atas menghadap samping, namum terdapat kelemahan yaitu terjadinya penutupan dari arah depan atau belakang objek. Maka dari itu diusulkan peletakan kamera dari atas (langit-langit ruangan) sehingga kamera dapat menangkap objek berupa orang, meja dan karpet yang memiliki ciri tersendiri pada masing-masing objek. Namun sudut pandang dari atas hanya dapat menangkap citra dengan luas cakupan yang terbatas, karena adanya keterbatasan jarak antara kamera dengan lantai. Untuk mengatasi persoalan tersebut, dibutuhkan hasil citra panorama (citra dengan cakupan area yang luas). Untuk mendapatkan citra panorama dapat digunakan sebuah metode pertautan citra (image stitching) dari area overlapping dua kamera agar sistem dapat memantau dalam bentuk panorama [2].

Pertautan citra dengan jarak objek yang sangat signifikan terhadap kamera (depth perception) [3] dan relatif dekat akan menghasilkan citra panorama dengan distorsi perspektif (menghasilkan objek ganda ataupun objek hilang) karena kamera memantau dalam bentuk dua dimensi dengan jarak horizontal antar kamera yang besar. Untuk mengatasi persoalan tersebut, dilakukan pertautan citra dengan segmentasi ROI perobjek dari dua USB kamera yang dapat memberikan persepsi kedalaman tiga dimensi dari dua citra dengan latar yang sama (stereoskopik), sehingga dapat diketahui informasi kedalaman suatu objek dengan cara yang intuitif dari corak warna dan cahaya [4].

Hasil pertautan citra tanpa adanya distorsi prespektif secara garis besar perlu dilakukan beberapa langkah seperti, segmentasi ROI (Region of Interest) atau pembagian objek [5] berupa bagian meja dan karpet secara manual karena objek meja dan karpet bersifat statis, pertautan citra antar masing-masing objek, penggabungan hasil pertautan objek meja dan objek karpet, dan menampilkan hasil penggabungan dari pertautan objek meja dan karpet. Segmentasi ROI meja dilakukan dengan menggunakan editor grafis secara manual yang menghasilkan masking atau citra hitam putih, objek meja berwarna putih dan selain meja berwarna hitam. Masking tersebut digunakan untuk memisahkan objek meja dan karpet. Dalam tahap pemisahan objek, program bekerja dengan cara mendeteksi warna putih atau bernilai 255, maka program akan menampilkan citra dengan warna asli ROI meja. Apabila sistem mendeteksi warna hitam atau bernilai 0 , maka program akan menampilkan citra dengan warna asli ROI karpet atau selain dalam ROI meja.

Masing-masing objek yang telah dipisah akan dilakukan pertautan. Langkah pertama yang dilakukan pada sistem pertautan yaitu deteksi fitur. Deteksi fitur merupakan proses komputasi abstraksi dari citra dan menetukan titik lokasi untuk melihat apakah terdapat fitur pada citra atau citra dari titik yang tersedia [6]. Beragam contoh pendeteksi fitur telah dihadirkan oleh penelitipeneliti sebelumnya, beberapa diantaranya yang relatif lebih populer adalah metode deteksi fitur SURF, SIFT, dan ORB. Salah satu penelitian pendeteksi fitur yang telah dilakukan ialah membandingkan kecepatan dan performa antara ORB, FAST dan SIFT. Hasil yang diperoleh adalah SIFT merupakan algoritma terbaik dalam mendeteksi objek[7]. SIFT (Scale Invariant Feature Transform) merupakan deteksi fitur yang terbukti sangat efisien dalam pengenalan objek. SIFT dapat digunakan untuk berbagai situasi seperti perubahan cahaya, resolusi, perubahan bentuk geometris, perputaran, dll [8].

Setelah deteksi fitur, dilakukan feature match atau pencocokan fitur-fitur yang telah didapat dari algoritme SIFT terhadap fitur-fitur pada citra atau citra lain untuk menemukan daerah pertautan yang tepat [9]. Kemudian menggunakan metode RANSAC (teknik resampling yang menggunakan minimum jumlah pengamatan) [10] untuk mendapatkan nilai homography matrix sebagai penyelaras citra atau memproyeksikan citra terhadap citra dari kamera lainnya sesuai dengan feature match yang didapat. Penggabungan hasil pertautan perobjek dilakukan

IJEIS Vol. 9, No. 2, October 2019: 183 - 192 
dengan cara mencocokkan koordinat dari objek meja terhadap karpet seharusnya berada. Kemudian didapatkanlah hasil citra dengan tautan meja dan karpet.

\section{METODE PENELITIAN}

\section{1 Analisis Penelitian}

Pada penelitian ini sistem yang akan dirancang dan dibangun merupakan sistem untuk menghilangkan distorsi perspektif pada pertautan citra dua kamera untuk mendapatkan tautan citra yang baik atau sempurna. Secara keseluruhan blok diagram penelitian ini dapat dilihat pada Gambar 1.

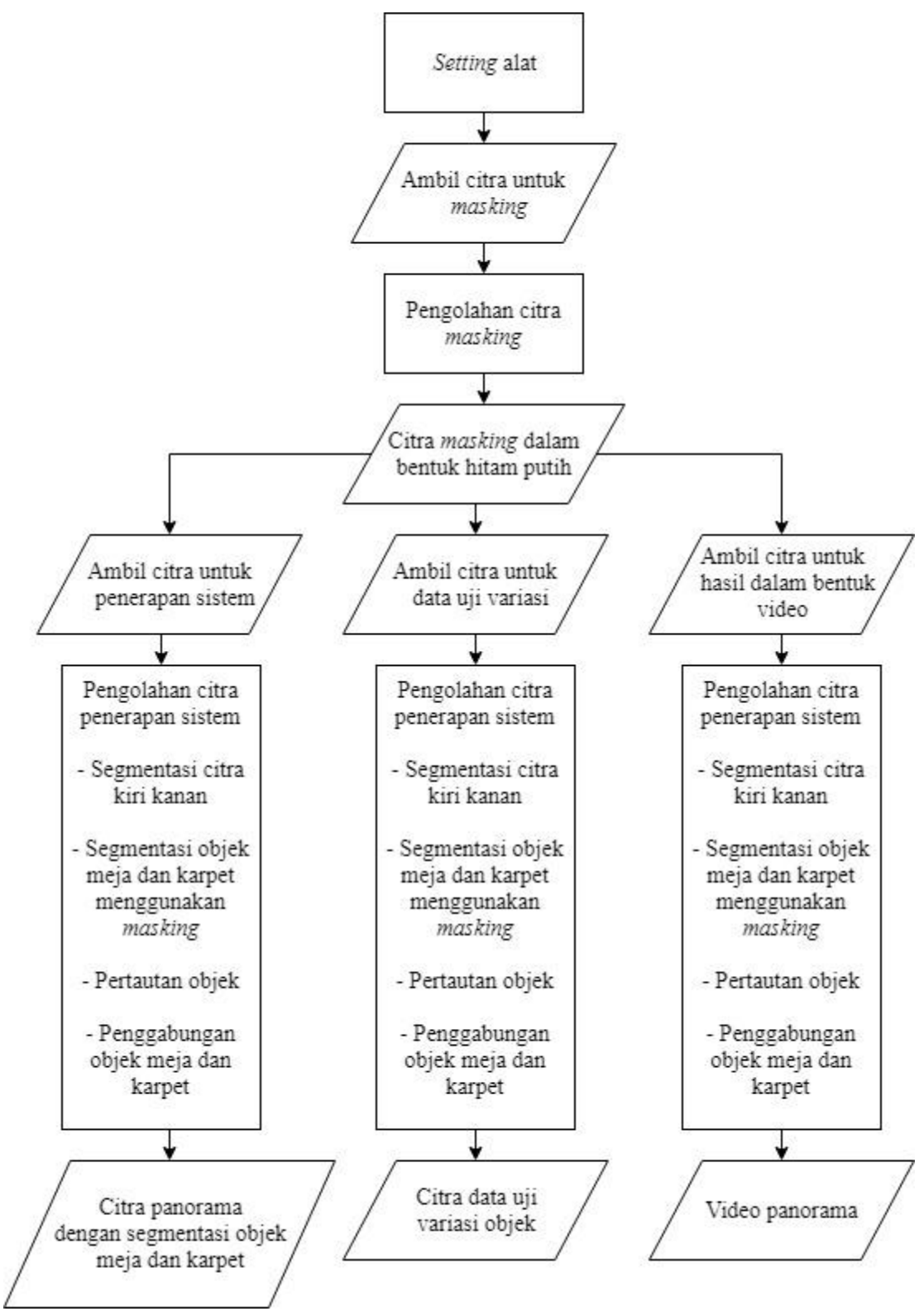

Gambar 1 Blok diagram penelitian

Beberapa langkah yang dilakukan dalam penelitian ini yaitu setting alat-alat yang dibutuhkan dalam penelitian ini seperti kamera, software yang digunakan, dan peletakan objek. Kedua yaitu pengambilan citra untuk dijadikan masking yang berupa citra hitam putih sebagai 
acuan dalam pemisahan objek meja dan karpet. Ketiga yaitu pengambilan dan pengolahan citra untuk penerapan sistem dengan hasil keluaran menjadi citra acuan atau citra yang dianggap baik dan sempurna dalam penelitian ini. Keempat yaitu pengambilan data uji variasi objek untuk mendapatkan nilai uji sistem terhadap variasi peletakan objek.

\section{2 Rancangan Sistem}

Penelitian ini menggunakan komputer dengan prosesor core i5, sistem operasi dasar Ubuntu 18.04 bahasa python 3.6.5 dan library openCV 3.4.2. Perangkat keras yang digunakan berupa laptop untuk melakukan pengolahan citra dan analisis data, dua USB kamera untuk menangkap citra yang dihubungkan ke SBC agar kamera mendapatkan alamat ip, sehingga kamera dapat diakses melalui laptop. Masing-masing kamera di pasang di langit-langit ruangan. Jarak vertikal antara kamera dengan lantai 3,13 meter, dan jarak antara kamera A dan B adalah 1 meter. Dengan menggunakan rancangan perangkat keras seperti pada Gambar 2 dihasilkan luasan overlapping dari dua citra sebanyak lebih kurang $48.46 \%$.

Gambar 2 merupakan rancangan perangkat keras yang akan digunakan.

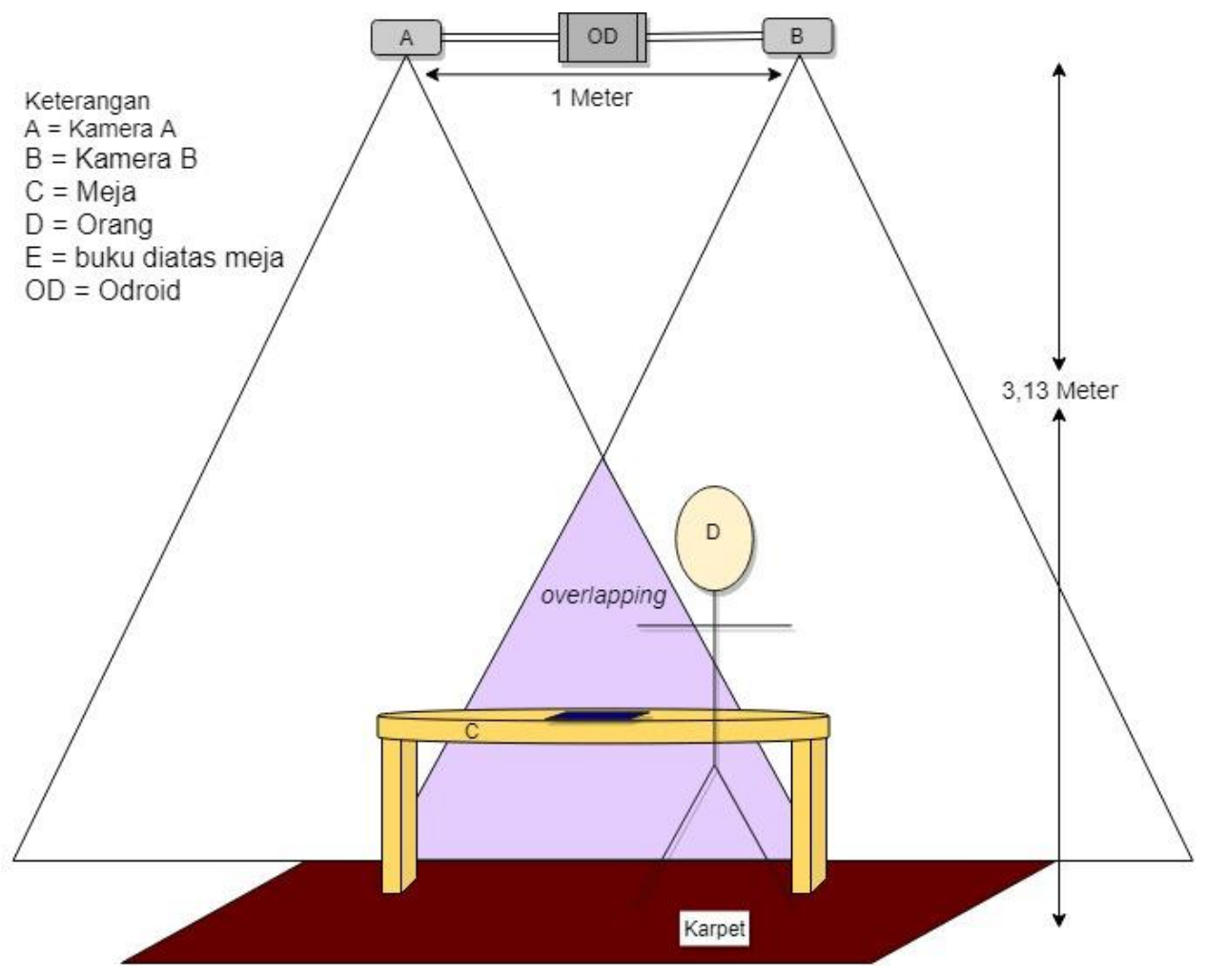

Gambar 2 Rancangan tempat pengambilan citra

\section{3 Rancangan Program}

Pemprosesan pada program terdiri dari beberapa langkah-langkah secara garis besar terdiri dari ambil citra dari dua kamera, potong citra menjadi citra kiri dan kanan, segmentasi ROI objek meja kiri dan kanan, pertautan objek meja karpet kiri dan kanan, penggabungan hasil pertautan objek meja dan karpet kemudian looping citra kedalam bentuk citra yang hasil 
akhirnya dalam bentuk citra yang dapat dilihat pada flowchart program secara keseluruhan seperti pada Gambar 3.

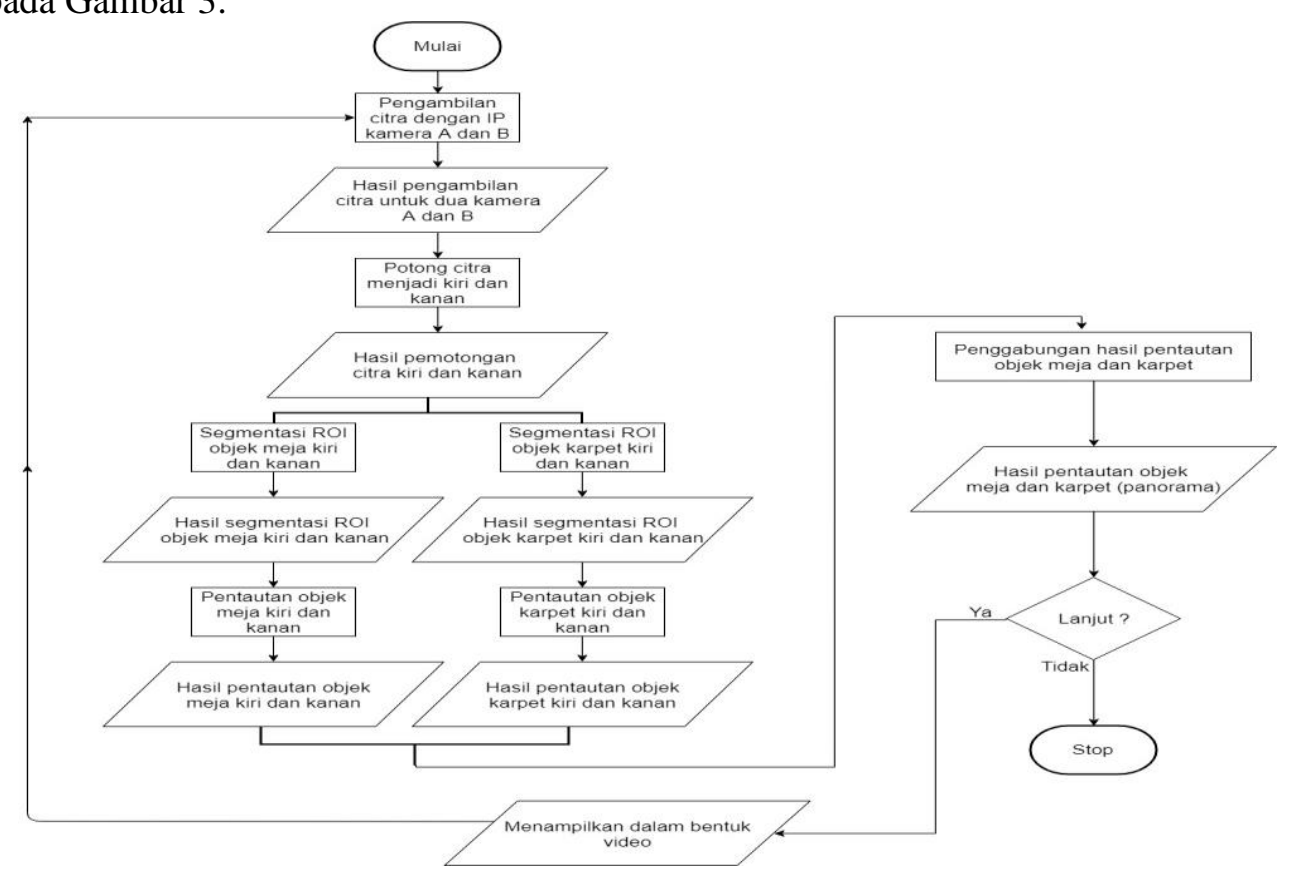

Gambar 4 Flowchart program keseluruhan

\section{4 Segmentasi Citra}

Segmentasi pertama kali dilakukan untuk memisahkan citra menjadi dua bagian yaitu citra dari kamera kiri dan citra dari kamera kanan. Selanjutnya, segmentasi ROI dari objek citra berupa meja dan karpet diimplementasikan karena pada penggunaan dua kamera terdapat persepsi kedalaman 3 dimensi terhadap benda yang memiliki ketinggian yang berbeda (meja dan karpet). Agar pada pertautan keypoint dapat dideteksi pada bagian karpet dan juga meja maka dilakukan segmentasi ROI objek. Segmentasi ROI dilakukan dengan menggunakan editor grafis secara manual yang menghasilkan citra hitam putih (masking), objek meja berwarna putih dan selain meja berwarna hitam. Masking tersebut digunakan untuk memisahkan objek meja dan karpet. Dalam tahap pemisahan objek, apabila sistem mendeteksi warna putih atau bernilai 255 (di program ditulis yang bernilai besar dari 100), maka program akan menampilkan citra dengan warna asli ROI meja yang diletakkan pada suatu wadah baru. Apabila sistem mendeteksi warna selain dari besar 100 atau lebih kecil dari 100 (hitam), maka program akan meletakkan pada suatu wadah yang beda dan menampilkan citra dengan warna asli ROI karpet atau selain dalam ROI meja. Kemudian terbentuklah dua citra baru atau dua citra dengan objek meja dan karpet yang sudah terpisah seperti Gambar 5.
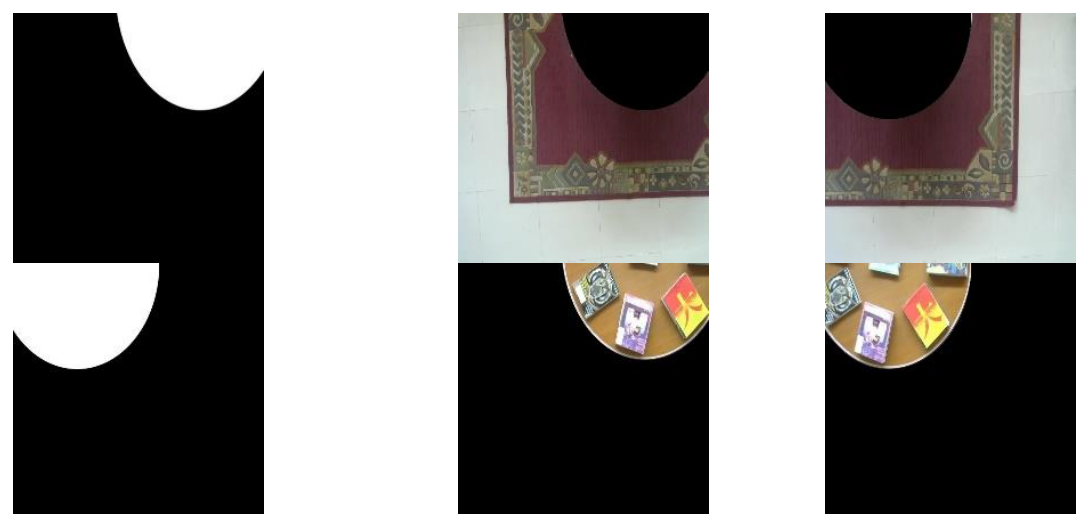
(a)

(b) (c)

Gambar 5 Segmentasi citra (a) masking (b) segmentasi objek kiri (c) segmentasi objek kanan

\section{5 Pertautan Citra}

Pertautan citra dilakukan sebanyak dua kali, yaitu untuk pertautan citra meja dan pertautan untuk citra karpet. Langkah-langkah dalam pertautan citra ialah deteksi dan ekstraksi fitur, pencocokan fitur, dan penggunaan perspective warp untuk mentautkan citra kiri dan kanan. Pertama, citra kiri dan kanan yang diolah akan dibaca untuk dicari fiturnya menggunakan descriptor SIFT. Setelah dilakukan deteksi dan ekstraksi fitur, dilakukan proses pencocokan fitur. Pencocokan fitur didapatkan dengan cara menjumlahkan kecocokan mentah dan inisialisasi daftar dari kecocokan yang sebenarnya menggunakan pembuat deksriptor BruteForce. Kemudian menghitung homography yang dibutuhkan sekurangnya 4 homography. Dari homography tersebut dibangun dua set titik atau point dan kemudian homography dari kedua set titik atau point tersebut dihitung. Agar homography dapat dihitung, digunakan beberapa parameter seperti matriks homography dan status dari setiap titik pencocokan. Setelah pencocokan fitur dilakukan perspective warp untuk mentautkan kedua citra antara kiri dan kanan. Dari pencocokan fitur yang telah dilakukan, didapatkan nilai M yang merupakan nilai untuk matches, matriks $\mathrm{H}$ dan status. Untuk hasilnya dilakukan warp perspective terhadap image A dengan masukan matriks $\mathrm{H}$ (homography), penjumlahan lebar dari citra $\mathrm{A}$ dan $\mathrm{B}$, dan tinggi dari citra A. Pada citra B tinggi dimulai dari titik nol, lebar sesuai dengan citra B. Karena proses pertautan citra dilakukan sebanyak dua kali, maka akan memberikan keluaran atau hasil sebanyak dua citra yang ditautkan seperti pada Gambar 6.

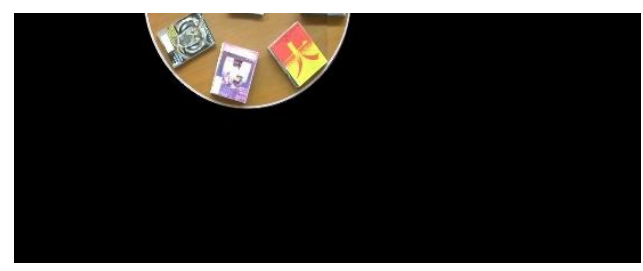

(a)

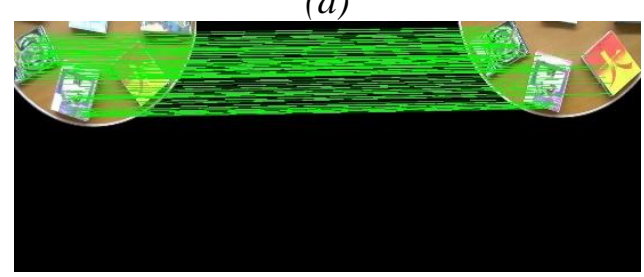

(c)

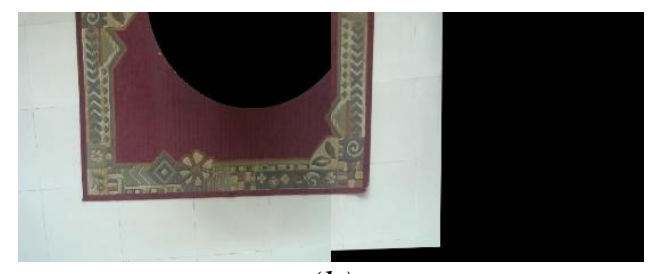

(b)

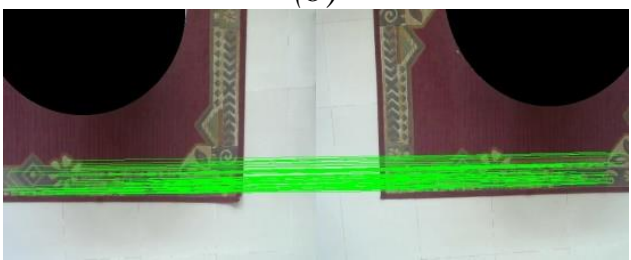

(d)

Gambar 6 Hasil pertautan citra (a) hasil pertautan objek meja (b) hasil pertautan objek karpet (c) keypoint meja (d) keypoint karpet

\section{6 Penggabungan Citra Hasil Pertautan Antar Objek}

Penggabungan citra hasil pertautan antar objek dilakukan dengan cara mencocokkan koordinat dari objek meja terhadap karpet seharusnya berada, kemudian didapatkanlah hasil panorama dengan tautan meja dan karpet. Citra meja dikonversikan menjadi grayscale, apabila citra meja bernilai hitam maka nilai piksel dari karpet akan diambil untuk menggantikan bagian yang hitam, sehingga didapatlah gabungan dari citra pertautan tiap-tiap objek seperti pada Gambar 7. 


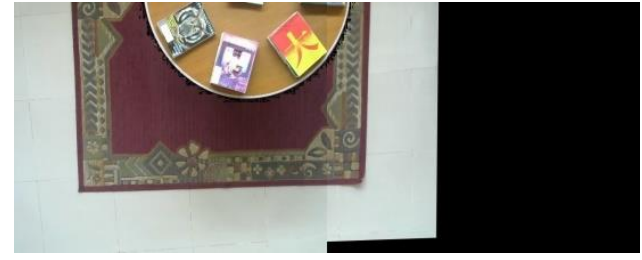

Gambar 7 Hasil penggabungan citra

\section{HASIL DAN PEMBAHASAN}

\section{1 Pengujian Terhadap Variasi Objek}

Proses pengujian dilakukan untuk melihat hasil dari sistem pengolahan citra yang telah dilakukan. Proses pengujian yang dilakukan pada setiap citra variasi diterapkan proses dan tahapan yang sama.

Variasi objek meja dengan buku dan karpet dapat dilihat pada Gambar 8 dan merupakan citra yang dijadikan sebagai acuan untuk percobaan sistem dan dianggap baik dan sempurna karena berhasil menghilangkan distorsi perspektif pada objek. Penerapan sistem yang dilakukan terhadap citra berhasil tetapi ada sedikit bagian corak karpet yang tertutupi karena ukuran meja menjadi relatif lebih besar.

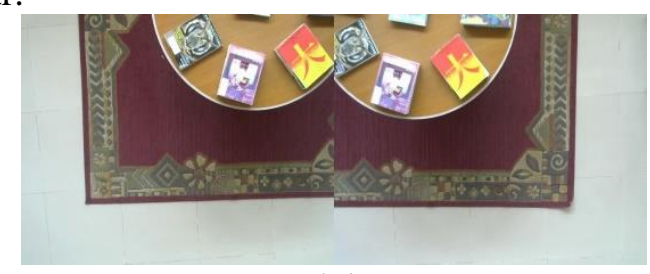

(a)

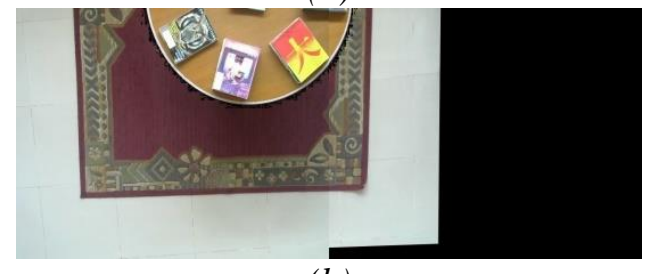

(b)

Gambar 8 Pengujian terhadap variasi objek (meja dengan buku dan karpet) (a) pengambilan citra (b) hasil penerapan sistem

Variasi objek meja dengan buku, orang dan karpet dapat dilihat pada Gambar 9. Pertautan berhasil dilakukan untuk citra objek meja sehingga pada saat proses penggabungan citra hanya dapat menampilkan pertautan objek pada meja. Pada saat pertautan perobjek, pertautan pada karpet gagal dilakukan karena keypoint mendeteksi corak yang sama dibagian kiri kanan karpet sedangkan corak dibagian lain tertutup oleh orang yang mana program tidak mendeteksi keypoint didalamnya.

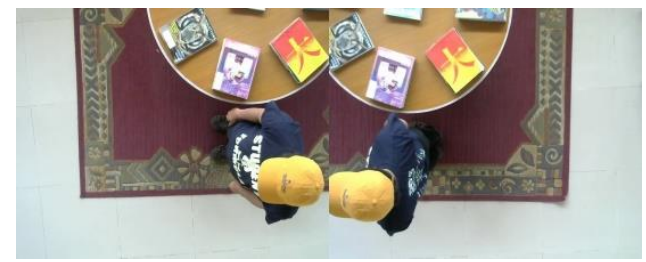

(a) 


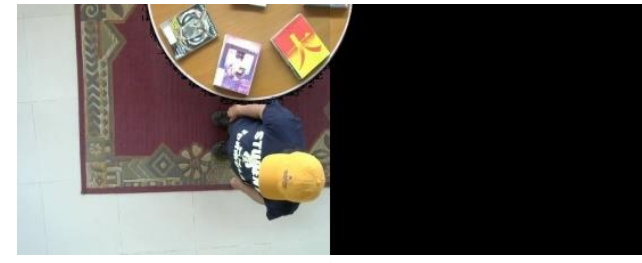

(b)

Gambar 9 Pengujian terhadap variasi objek (meja dengan buku, orang dan karpet) (a) pengambilan citra (b) hasil penerapan sistem

Variasi objek meja tanpa buku dan karpet dapat dilihat pada Gambar 10. Proses pertautan pada meja tidak berhasil dilakukan karena tidak terdapat cukup keypoint pada daerah meja tetapi pada pertautan karpet menghasilkan hasil pertautan yang sempurna.
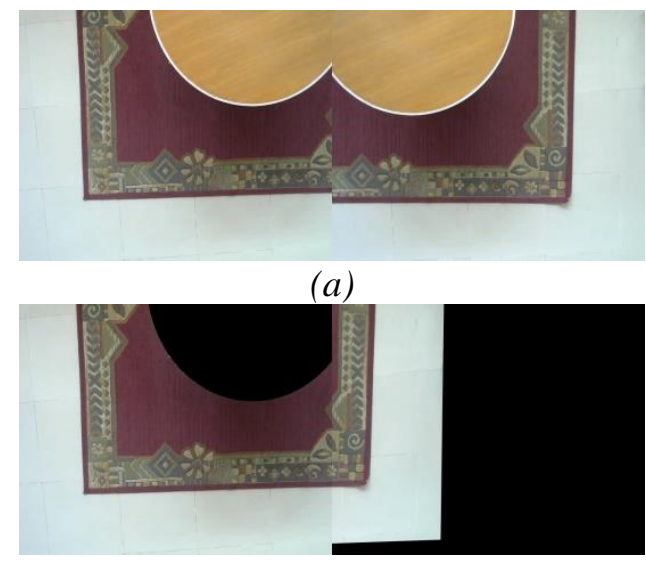

(b)

Gambar 10 Pengujian terhadap variasi objek (meja tanpa buku dan karpet) (a) pengambilan citra (b) hasil penerapan sistem

Dari pengujian yang dilakukan terhadap variasi objek, sistem tidak dapat beradaptasi otomatis dengan perubahan letak objek karena segmentasi bersifat statis dan manual dengan koordinat yang tetap. Sistem hanya bagus diterapkan pada keadaan meja dengan buku dan karpet tanpa orang, namun untuk orang atau objek lain bisa ditambahkan asalkan tidak berada pada bagian overlap kamera. Apabila hendak menambahkan orang pada bagian overlap, sistem juga harus ditambahkan segmentasi orang. Sehingga akan ada 3 bagian objek yang dipisahkan.

\section{2 Analisis Perbandingan Pertautan Citra}

Pengujian perbandingan hasil pertautan citra dilakukan untuk melihat sistem mana yang lebih baik antara hasil pertautan citra menggunakan segmentasi ROI objek dengan hasil pertautan citra tanpa segmentasi ROI objek yang dapat dilihat pada Gambar 11.

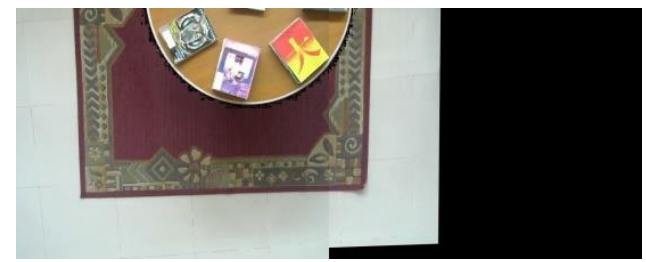

(a) 


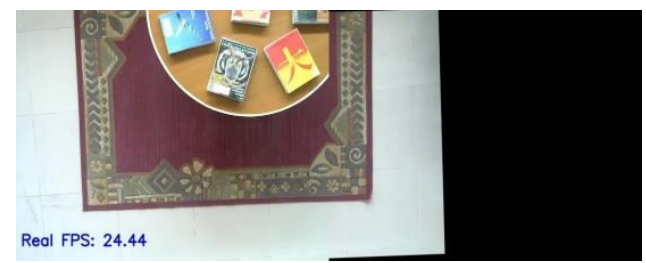

(b)

Gambar 11 Hasil pertautan citra (a) menggunakan segmentasi ROI objek (b) tanpa menggunakan segmentasi ROI objek

Dapat dilihat dari hasil yang didapat bahwa, pertautan menggunakan segmentasi ROI objek menghasilkan gambar yang utuh untuk tiap-tiap objek (meja dan karpet) dan objek meja menjadi lebih besar karena berada pada jarak yang lebih dekat ke kamera. Untuk pertautan tanpa segmentasi ROI objek terjadi pembuangan citra meja bagian kanan karena keypoint hanya mendeteksi bagian lantai dan mengabaikan lainnya. Begitupun apabila keypoint mendeteksi bagian meja, maka pada citra karpet akan terjadi objek ganda. Hal tersebut terjadi karena keypoint hanya fokus mendeteksi pada salah satu objek dengan ketinggian yang berbeda.

Dengan menerapkan sistem segmentasi ROI objek, maka dapat menghasilkan citra dengan tautan yang meminimalisir adanya objek ganda ataupun terbuang karena pertautan dilakukan pada tiap-tiap objek yang disegmentasi. Walaupun citra panorama tanpa adanya objek yang terpotong ataupun ganda dapat diatasi, namun penelitian ini menghasilkan citra panorama yang kurang bagus karena tidak mempengaruhi scaling yang menyebabkan objek meja menjadi lebih besar dan menutupi sebagian dari karpet yang dikarenakan pada proses pertautan (perspective warp) hanya citra kanan yang menyesuaikan citra kiri sehingga perlakuan sistem hanya terjadi pada salah satu citra. Penerapan sistem panorama dua kamera ini menghasilkan penambahan citra sebesar $17,7 \%$ daripada sistem dengan satu kamera.

\section{KESIMPULAN}

Berdasarkan hasil pengujian yang telah dilakukan, maka dapat ditarik kesimpulan bahwa pertautan dua citra dari dua kamera yang berjarak 1 meter yang ditempatkan di langit-langit bejarak 3,13 meter dari lantai dengan penerapan sistem pertautan dengan segmentasi ROI objek dapat meminimalisir terabainya atau munculnya objek ganda. Citra ganda terjadi karena keypoint hanya mendeteksi objek diatas meja dan pertautan terjadi dimeja yang menyebabkan penggeseran citra kanan pada saat proses pertautan perspective warp hanya sedikit saja, sehingga menghasilkan citra karpet yang ganda atau terjadinya penampakan objek yang sama persis dari kamera a dan b. Citra terpotong atau terbuang terjadi karena keypoint hanya mendeteksi objek karpet dan pertautan terjadi dikarpet yang menyebabkan penggeseran citra kanan pada saat proses pertautan perspective warp lebih banyak, sehingga menghasilkan citra meja yang terpotong.

\section{SARAN}

Beberapa saran untuk pengembangan penelitian selanjutnya ialah menghadirkan segmentasi yang bisa beradaptasi terhadap variasi letak objek (otomatis), dapat melakukan variasi jarak antar kedua kamera agar didapatkan nilai overlapping terkecil untuk citra panorama yang lebih luas, dapat memperhatikan bagian scaling agar objek yang dihasilkan tetap sama besar dan tidak menutupi objek lainnya dan penelitian lebih lanjut diharapkan dapat memberikan perlakuan yang sama kepada kedua citra kiri dan kanan pada saat pertautan perspective warp sehingga citra panorama yang dihasilkan lebih besar dan luas. 


\section{DAFTAR PUSTAKA}

[1] Aung, N.L., D, K.V., Ye, K.Z. dan Htet, Z.W., 2018, The Study of the Process of Stitching Citra Images in Real Time, (1), 1831-1834,

[2] Fathima, A.A., Karthik, R. dan Vaidehi, V., 2013, IMAGE STITCHING WITH COMBINED MOMENT INVARIANTS AND SIFT FEATURES, Procedia - Procedia Computer Science, [Online] 19 (Ant), 420-427, tersedia di DOI:10.1016/j.procs.2013.06.057.

[3] Emoto, M., 2019, Depth perception and induced accommodation responses while watching high spatial resolution two-dimensional TV images, Displays, [Online] 60 (August), 24-29, tersedia di DOI:10.1016/j.displa.2019.08.005.

[4] Flavia, D.X., Meier, M., Karim, D.X. dan Horlick, M., 2019, Validation of Quantitative 3Dimensional Transesophageal Echocardiography Mitral Valve Analysis Using Stereoscopic Display, Journal of Cardiothoracic and Vascular Anesthesia, [Online] 33 (3), 732-741, tersedia di DOI:10.1053/j.jvca.2018.08.013.

[5] Ahmed, S.E., Cheung, L., Shaban, M., Graham, S., Epstein, D., Pelengaris, S., Khan, M. dan Rajpoot, N.M., 2019, Micro-Net: A unified model for segmentation of various objects in microscopy images Medical Image Analysis, [Online] 52160-173, tersedia di DOI:10.1016/j.media.2018.12.003.

[6] Setiyawan, A., 2014, Pencocokan Citra Berbasis Scale Invariant Feature Transform (SIFT) menggunakan Arc Cosinus, Jurnal Teknik Informatika, 1-4,

[7] Karami, E., Prasad, P. dan Shehata, M., 2015, Image Matching Using SIFT, SURF, BRIEF and ORB: Performance Comparison for Distorted Images, 1-5,

[8] Guo, F., Yang, J., Chen, Y. dan Yao, B., 2018, Research on image detection and matching based on SIFT features, 2018 3rd International Conference on Control and Robotics Engineering, ICCRE 2018, [Online] 130-134, tersedia di DOI:10.1109/ICCRE.2018.8376448.

[9] Putra, F. dan Gunadi, K., 2014, Aplikasi Automatic Image Stitching pada Kumpulan Gambar dalam Satu Scene, Jurnal INFRA, 250-54,

[10] Dewanti, F. dan Sumiharto, R., 2015, Purwarupa Sistem Penggabungan Foto Udara Pada UAV Menggunakan Algoritma Surf ( Speeded-Up Robust Features ) 1, 5 (2), 